\title{
Using DIC techniques to measure strain ranges inside the cyclic plastic zone ahead of a fatigue crack tip
}

\author{
Giancarlo Luis Gómez Gonzáles, Julián Andrés Ortíz González, Jaime Tupiassú Pinho de Castro, \\ José Luiz de França Freire. \\ Pontifical Catholic University of Rio de Janeiro, PUC-Rio, R. Marquês de São Vicente 225, Rio de Janeiro, 22451-900, Brazil \\ gonzalesglg@aaa.puc-rio.br,julian@aluno.puc-rio.br,jtcastro@puc-rio.br,jlfreire@puc-rio.br
}

\begin{abstract}
A stereo microscope coupled to a 3-D Digital Image Correlation system is used to measure strain ranges on the cyclic plastic zone ahead of a fatigue crack-tip. First, a very refined speckle pattern is applied on the surface of a disk-shaped compact tension specimen of 1020 low-C steel by spraying toner powder over a layer of white paint, a suitable technique to produce the very small dots needed to map surface strain loops on that small region. This technique can achieve enough resolution to measure elastoplastic strain ranges $\Delta \varepsilon$ near the crack tip, which cause damage accumulation inside the cyclic plastic zone as the crack grows. The applied technique can identify as well the effects of other nonlinear phenomena that happen in the near-tip region, such as crack closure. Therefore, such measurements can be used to verify the validity of the hypotheses behind the main fatigue crack growth models.
\end{abstract}

KEYwORDS. Digital Image Correlation; Crack-tip strain field; Cyclic plastic zone; Damage ahead of the crack tip; Stereo microscope measurements.

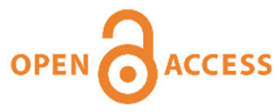

Citation: Gonzales G.L.G., González J.A.O., Castro J.T.P., Freire J.L.F. DIC techniques to measure strain ranges inside the cyclic plastic zone ahead of a fatigue crack tip, Frattura ed Integrità Strutturale, 49 (2019) 74-81.

Received: 01.03.2019 Accepted: 30.04 .2019 Published: 01.07.2019

Copyright: (C) 2019 This is an open access article under the terms of the CC-BY 4.0, which permits unrestricted use, distribution, and reproduction in any medium, provided the original author and source are credited.

\section{INTRODUCTION}

S ince purely reversible elastic strains do not cause damage, elastoplastic (EP) strain ranges induced by cyclic plastic deformations are a necessary condition for any fatigue process. Therefore, it is a truism to say that the behavior of the plastic zones that always accompany fatigue crack tips is of great important for the understanding of fatigue crack growth (FCG) problems. There are many models to estimate what happens inside such plastic zones, from elementary analytical formulas to sophisticate numerical analyses [1-9]. Due to the severe stress concentration induced by fatigue crack tips, two such zones always form ahead of them, the monotonic plastic zone and the cyclic one, see Fig. 1. The simplest estimates for the sizes of such plastic zones are, respectively, $p_{z}=(1 / \pi)\left(K_{\max } / S_{Y}\right)^{2}$ and $p_{\xi_{c}}=(1 / \pi)\left(\Delta K / 2 S_{Y_{c}}\right)^{2}$, according to the Irwin's model. In these equations, $K_{\max }$ and $\Delta K$ are the peak and the range of the stress intensity factors (SIF) induced by the loading, whereas $S_{Y}$ is the monotonic and $S_{Y_{c}}$ is the cyclic yield strength of the material. Albeit elementary, such estimates are useful in practical applications because in most FCG problems almost all of the FCG lives are spent under small scale yielding conditions. Moreover, they justify the claim that $\Delta K$ and $K_{\max }$ are the two driving forces for FCG, the 
first associated with pure cyclic damage and the second with complementary damage mechanisms controlled by the peak SIF, such as environmentally assisted cracking, fracture, tearing, etc [10]. However, the measurement of what really happens inside such plastic zones still presents many non-trivial experimental challenges. The main problems are associated with the small size of such zones; with the strong strain gradients inside them, in particular near the crack tips; and with the material anisotropy in such size scale.

Fig. 1 shows a schematic diagram of the expected mechanical behavior of the material inside the unbroken residual ligament ahead of a fatigue crack tip, at least in phases I (the near threshold) and II (the Paris' region) of the FCG process. Relatively far from the crack tip, outside the plastic zones, the material does not suffer plastic deformations, thus it is cycled under purely linear-elastic (LE) conditions. In the monotonic plastic zone, controlled by $K_{\max }$, the material yields in tension during the loading of the cracked component, but does not suffer reverse yielding during its unloading. In the reversed or cyclic plastic zone close to the crack tip, primarily controlled by $\Delta K$, the material yields in tension during the loading and in compression during the unloading of the cracked component. Such reverse yielding process always occur ahead of propagating fatigue crack tips due to their very high stress concentration factors.

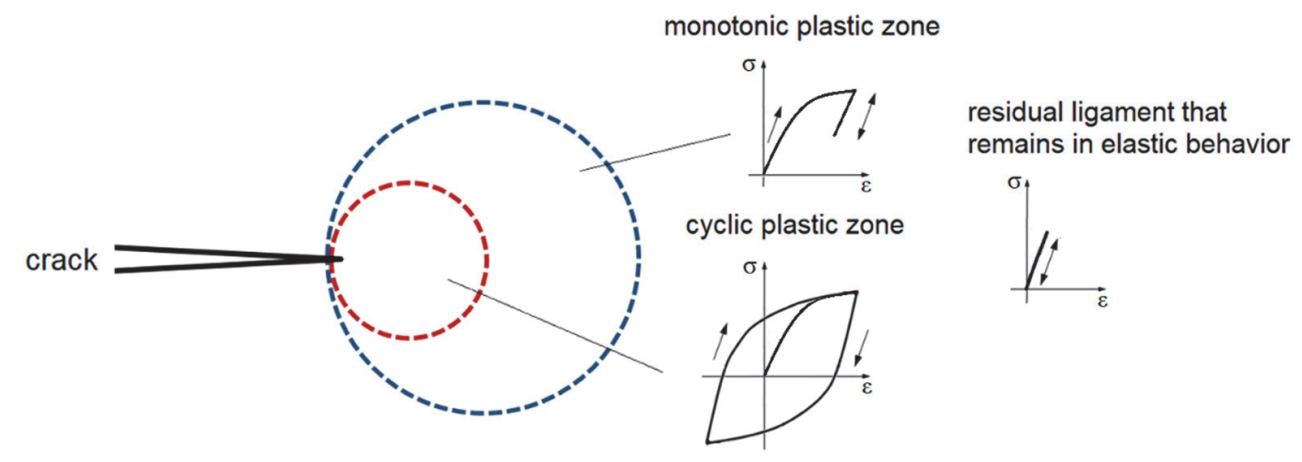

Figure 1: Expected stress-strain response of the different zones surrounding the crack tip (adapted from [6]).

One way to explain the FCG behavior is to assume it is caused by the sequential breaking of small volume elements (VE) of material previously damaged by elastoplastic hysteresis loops, as shown in the Fig. 2 [11-14]. This so-called critical damage model, as well as most other models proposed to explain and eventually to quantify the FCG process, associate it with what happens inside the plastic zones, because it is there where fatigue damage accumulation is most severe.

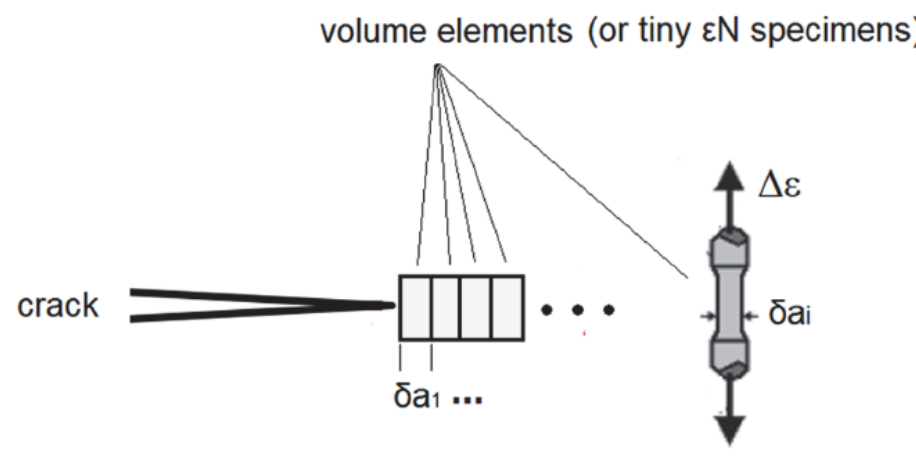

Figure 2: Schematics of how fatigue crack tips grow by successive fractures of the VE adjacent to its tip.

Experimental investigations of the plastic zone behavior can use Digital Image Correlation (DIC) techniques [15], but they need to be coupled to suitable optical microscopy systems to obtain full-field deformations at small length scales. Tong et al [16] reported near-tip strain ratcheting under cyclic loading using two independent experiments, Stereo-DIC and scanning electron microscopy SEM system, respectively. The results show the evolution of the maximum normal strain with cycles, although the evolution during the cyclic loading is lacking. Similar study was made by Lu [17] by using a single camera coupled with a high-resolution lens. Zhang et al [18] performed a study of the crack-tip plastic deformation behavior using an in situ optical microscopy fatigue testing system and 2D-DIC analysis. Experimental measurements show estimations of the plastic zone size within one cyclic loading and the strain distribution along the crack plane. Carroll et al [19] studied the plastic strain accumulation associated with fatigue crack growth at grain level using combined in situ and ex situ DIC 
techniques, optical microscopy and SEM system, respectively. Albeit all these works present important experimental measurements in the near-tip region, an adequate characterization of its cyclic plastic zone is lacking in what concerns the cyclic plastic deformation behavior near the crack tip (i.e. formation of hysteric loops) considering nonlinear phenomena that happen during FCG such as the crack closure [20], crack tip plasticity and other mechanisms [21-22]. Thus, the main contribution of this work is to provide experimental data from the cyclic plastic zone that can be used to support FGC model hypotheses, and particularly the critical damage models.

\section{EXPERIMENTAL PROCEDURE}

7 he material used for this investigation is the AISI 1020 steel. A disk-shaped compact tension (DCT) specimen was machined from a 3" steel round bar to a thickness of $5 \mathrm{~mm}$. Specimen geometry and dimensions are shown in Fig. 3.

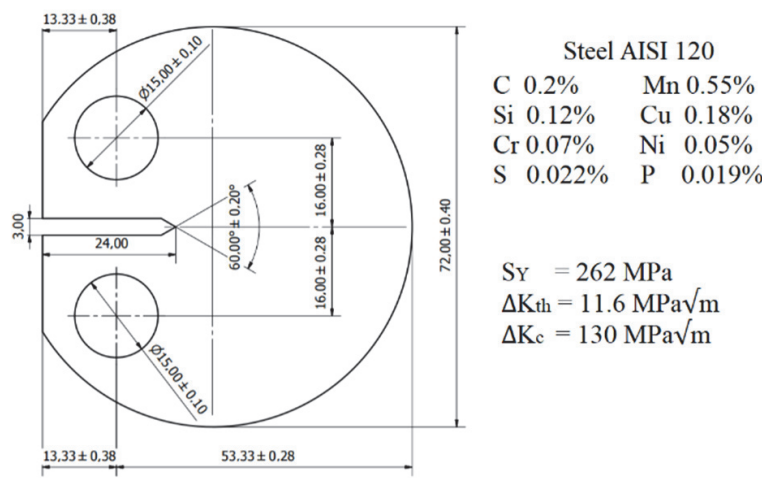

Figure 3: Specimen dimensions and chemical composition.

A fatigue crack was grown in mode I under constant $\Delta K$ conditions at $\mathrm{R}=0.1$ and $5 \mathrm{~Hz}$ in a servohydraulic fatigue testing machine with a capacity of $\pm 100 \mathrm{kN}$. Two different $\Delta K$ amplitudes were applied to the specimen. First, the crack was propagated until a length of $10 \mathrm{~mm}$ under $\Delta K=20 \mathrm{MPa} \sqrt{\mathrm{m}}$, and after the load was increased to $\Delta K=30 \mathrm{MPa} \sqrt{\mathrm{m}}$. To perform the test, a dedicated LabVIEW program was developed to update the force applied to the specimen needed to maintain the constant $\Delta K$ conditions, using a strain gage bonded on the back face of the specimen to measure the crack length by the compliance method [23].
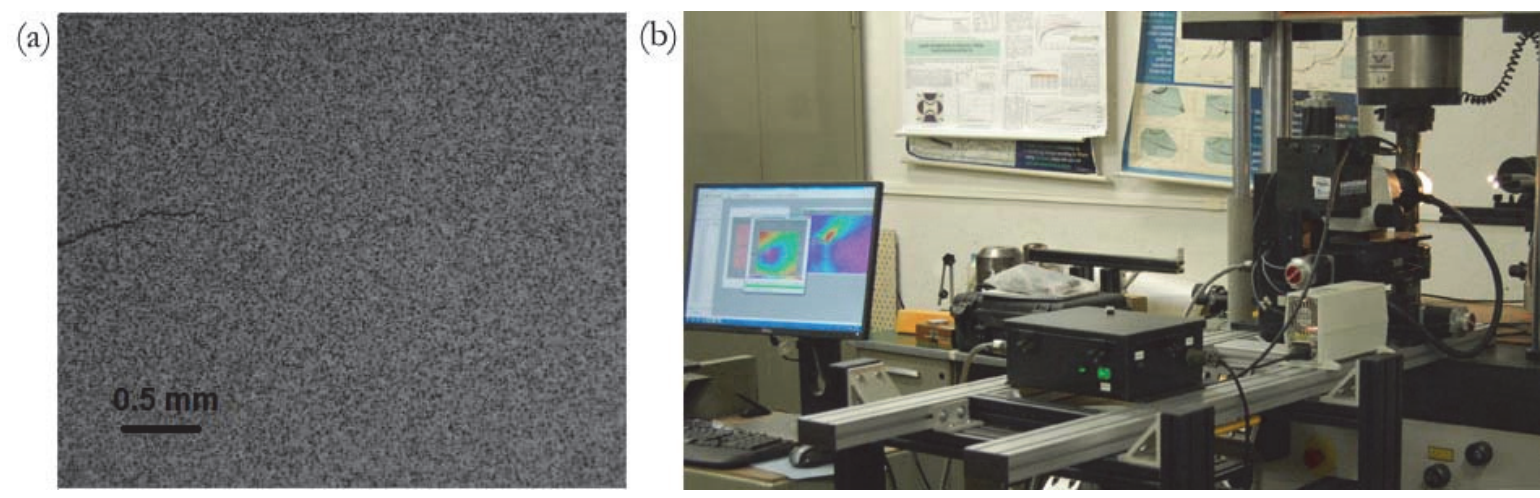

Figure 4: (a) Toner powder pattern and (b) experimental setup used for the experiments.

The DIC measurements were performed by a VIC-3D Microsystem [24] with a stereo microscope (Olympus SZX16) equipped with two 5.0 megapixel CCD cameras and mounted on a 3-axis motorized stage for fine position control. This system uses a patented stereo microscope distortion correction software module which computes the non-parametric distortion fields of the stereo microscope to eliminate shape and strain bias from the measurements and overcome the problems associated with obtaining 3D measurements under high magnification. In this study, the stereo microscope was 
configured to analyze an area of about $3 \times 3.5 \mathrm{~mm}$ on the specimen surface. The calibration of stereo cameras was performed with a standard calibration grid of $15 \times 15$ dots with dot spacing of $110 \mu \mathrm{m}$. The speckle pattern on specimen surface required to achieve a high resolution in DIC measurements was created by carefully spraying toner powder over a white paint background. The speckle pattern and experimental setup used for DIC analysis are presented in Fig. 4.

\section{EXPERIMENTAL RESULTS}

$\mathrm{I}$ mages from the FCG test were captured during consecutive load cycles after the introduction of the new $\Delta K$ range of higher amplitude and, after the crack propagates about $1 \mathrm{~mm}$ under the same FCG conditions, as indicated in the schematic of the Fig. 5. During the acquisition of the images, the test frequency was reduced to $0.01 \mathrm{~Hz}$ in order to obtain 100 images every cycle.

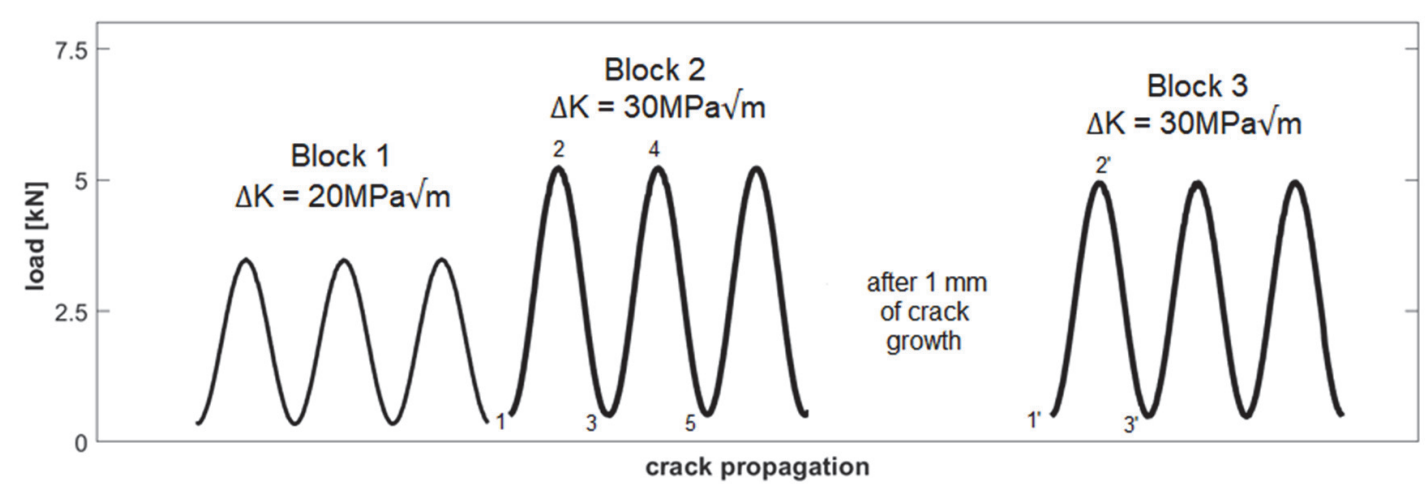

Figure 5: The loading history for image acquisition

The DIC analysis was conducted using a larger subset size of 41 pixels in order to ensure that the information inside the subset can be distinguished from all other subset. Step size of 11 pixels and strain window of 19 data points were used for all the samples. The correlation algorithm used was normalized-sum-of-squared-differences with optimized 8-tap interpolation to compensate for subset smoothing by using a larger subset. All DIC parameters were chosen in accordance with the Good Practices Guide for DIC [25] developed by the iDICs. From the analysis of two static images, the strain resolution of the measurements is on the order of $120 \mu \varepsilon$ which is suited to plastic deformation studies. Moreover, since the pixel resolution is about $1.6 \mu \mathrm{m}$, the subset or element used for correlation has an area of $65.6 \times 65.6 \mu \mathrm{m}^{2}$ and they are computed every $17.6 \mu \mathrm{m}$. These settings give a virtual strain gauge (VSG), or area needed to calculate the strain, of 199 pixel or $320 \mu \mathrm{m}$.

Assuming Irwin's estimate, the monotonic plastic zone in plane stress conditions is about $p z=(1 / \pi) \cdot\left(K_{\max } / S_{Y}\right)^{2}=2.29 \mathrm{~mm}$ for the loading block 1 under $\Delta K=20 \mathrm{MPa} \sqrt{\mathrm{m}}_{\mathrm{m}}$. The size of the cyclic or reversed plastic zone can also be estimated in a first approximation by $p_{z_{c}}=(1 / \pi) \cdot\left(\Delta K / 2 S_{Y}\right)^{2}=0.5 \mathrm{~mm}$. More precisely, the yield strength $S_{Y}$ in $p_{z_{c}}$ equation should be replaced by the cyclic yield strength $S_{Y_{c}}[3]$. It is worth to emphasize that in these analytic equations, the plastic zone is treated as a circle in front of the crack tip and nonlinear phenomena (such as crack closure, crack tip blunting, crack tip plasticity and others) are not taking into account. It is clear that increasing the size of the cyclic plastic zone resulted in improvement in quantitative strain measurements in the near-tip region. Therefore, for the loading block 2 under $\Delta K=30$ $\mathrm{MPa} \sqrt{\mathrm{m}}$, the estimates for the plastic zone is $p z=5.15 \mathrm{~mm}$ and its corresponding cyclic plastic zone is $p z=1.04 \mathrm{~mm}$.

In this test, the normal strain $\varepsilon_{y y}$ parallel to the load direction and perpendicular to the macroscopic direction of the crack growth was evaluated. Fig. 6 shows the strain behavior at $0.1 \mathrm{~mm}$ from the crack tip for the three loading blocks shown in Fig. 5. Fig. 6a shows the strain behavior during loading block 1. In this figure, the change in slope observed in the load versus strain curve is related to the crack closure phenomenon caused by residual deformations appearing behind the crack tip during fatigue cracking process. Fig. $6 \mathrm{~b}$ shows the near-tip strain evolution during the introduction of the loading block 2 with a higher $\Delta K$ range. It can be observed that the high levels of plastic deformation ahead of the crack tip during the first loading phase $1 \rightarrow 2$ (see Fig. 5) produces a plastic deformation that blunts the tip of the crack, reducing or eliminating the nonlinear behavior observed in the previously loading block. It is also noticed that the cyclic deformation in subsequent cycles exhibits a closed hysteresis loops similar or according to Masing behavior [26] with high levels of plastic strain formed during the loading path which are totally or quasi-totally reverted during the unloading path. Later, Fig. 6c shows the strain 
behavior after the crack has propagated $1 \mathrm{~mm}$ under the same $\Delta K$ range. In this case, the hysteresis loops formed ahead of the crack tip show a smaller amplitude and a shape that clearly differs from the previous behavior, particularly at low loads. This strain behavior can be related to the stabilization of crack propagation after the introduction of the new $\Delta K$ range, and consequently, the reappearance of the mechanisms that acts behind the crack tip during fatigue cracking process. Moreover, it can be observed that, despite the nonlinear behavior of the crack, the plastic strain formed during the loading path is totally or quasi-totally reverted during the unloading path.
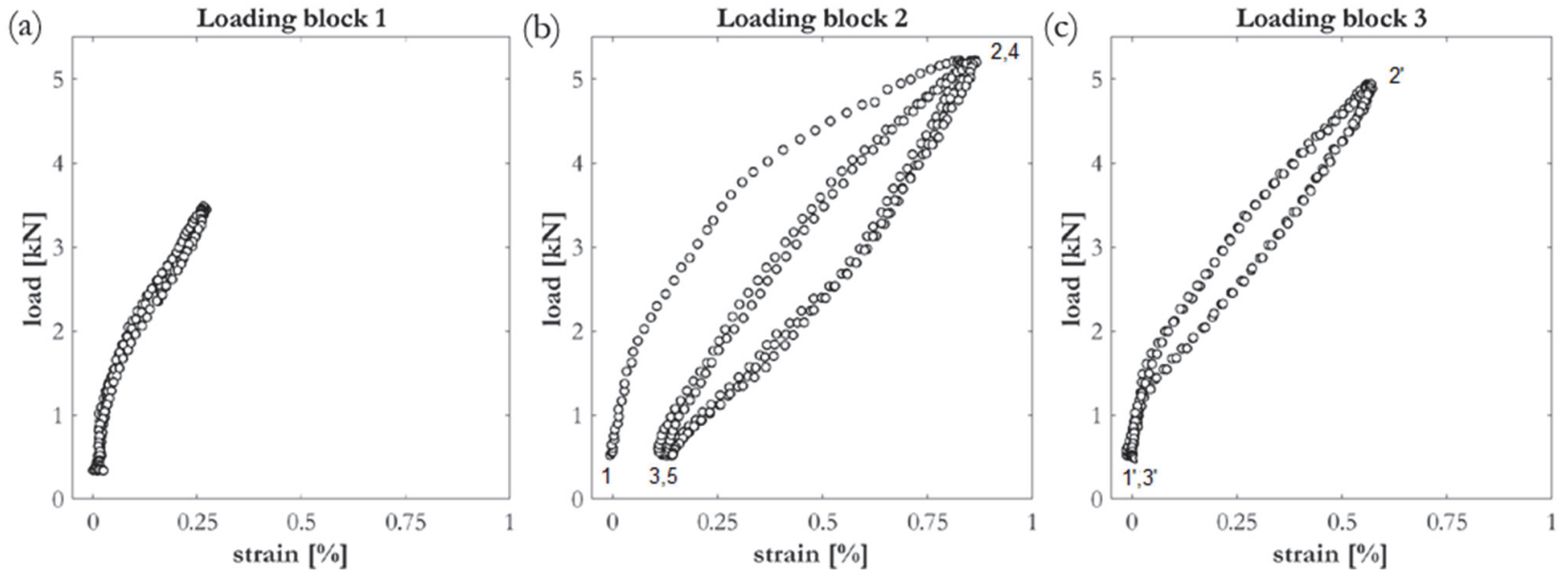

Figure 6: Strain behavior at $0.1 \mathrm{~mm}$ from the crack tip.

Besides, Figs. 7 and 8 show the strain field that develops around the crack tip at different loading and unloading paths of loading blocks 2 and 3. It can be seen that data surrounding the crack faces was excluded from the analysis to avoid undesired noise levels associated with abrupt changes in displacement. Fig. 7a shows the strain field during the first loading phase, 1 $\rightarrow 2$. The strain map exhibits an elongated shape with high values of plastic deformation contained in the near-tip region. It is clear that the increase on the value of the $K_{\max }$ leads to a larger plastic zone size, as well as the increase of the $\Delta K$ range produces a larger cyclic plastic zone. Fig. 6b shows the strain field during the subsequent unloading phase, $2 \rightarrow 3$ (see Fig. 5). In this case, DIC analysis used the image captured at the maximum loading as reference image and the image captured at the minimum loading as deformed image. In this way, it is expected that the strain values during the unloading phase will have negative signal. The strain map obtained from the unloading process indicates that the material experienced an elastic recovery and just ahead of the crack tip, the material deformed plastically. From these results, it can be verified that the higher $K_{\max }$ increases the size of the primary plastic zone formed during the first loading phase, $1 \rightarrow 2$. After, a much smaller plastic zone is formed during the unloading path, $2 \rightarrow 3$, the so-called reversed/cyclic plastic zone.

(a)

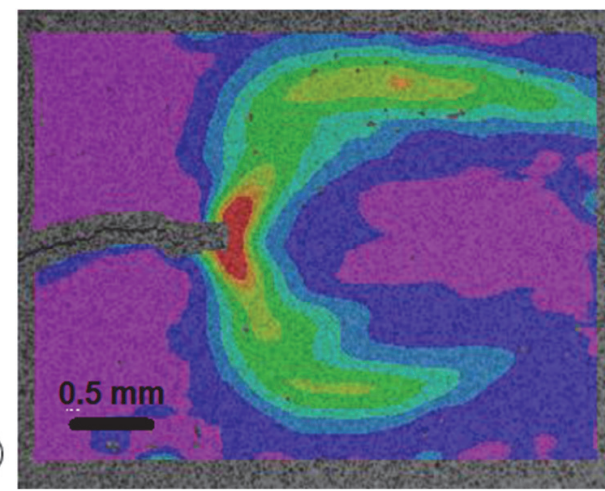

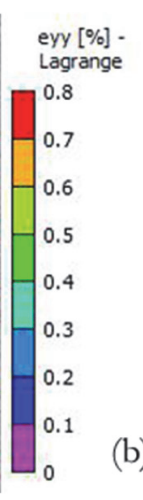

(b)

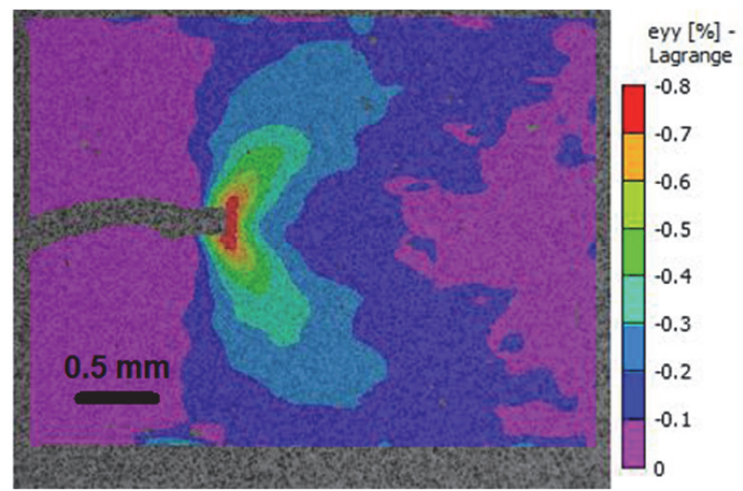

Figure 7: Strain map data for loading path $1 \rightarrow 2$ and unloading paths $2 \rightarrow 3$ from loading block 2 .

Figs. 8 and 9 show the strain field around the crack tip in subsequent cycles after the introduction of higher $\Delta K$ range. It is clear that after cycling another type of plastic zone is formed. Figs. 8a shows the cyclic plastic zone developing during loading path $3 \rightarrow 4$ (see Fig. 5), while Fig. 8b shows the cyclic plastic zone appearing during unloading $4 \rightarrow 5$ (see Fig. 5). Besides, Figs. 9a and 9b corresponds to the loading path 1' $\rightarrow$ 2' (see Fig. 5) and unloading path 2' $\rightarrow$ 3' (see Fig. 5), 
respectively. In this cases, the cyclic plastic zones developing during loading and unloading are similar in shape and size. Comparing the strain maps from Fig. 8 and 9, it is verified that the plastic strain levels are larger at loading block 2 (immediately after the change in $\Delta K$ range) than loading block 3 (after the crack has propagated $1 \mathrm{~mm}$ ). As mentioned in the previously analysis, this difference is related to the absence or presence of nonlinear phenomena that take place in the vicinity of the crack tip during application of the higher $\Delta K$ and subsequent crack propagation. In addition, Fig. 10 offers additional information about the strain behavior for different measurement points located ahead of the crack tip for loading blocks 2 and 3. It can be observed that the plastic strain levels decrease as the point of measurement is located away from the crack tip, leaving the region hypertrophied by the plastic zone and moving to the residual ligament that remains in elastic behavior.

(a)
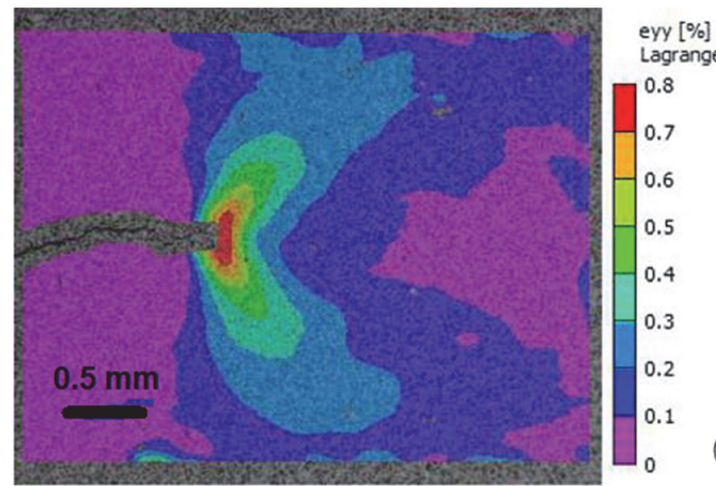

(b)

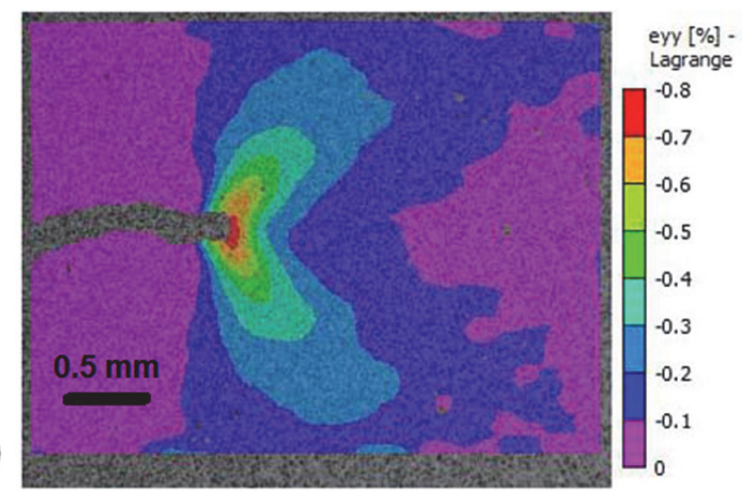

Figure 8: Strain map data for loading path $3 \rightarrow 4$ and unloading path $4 \rightarrow 3$ from loading block 2 .

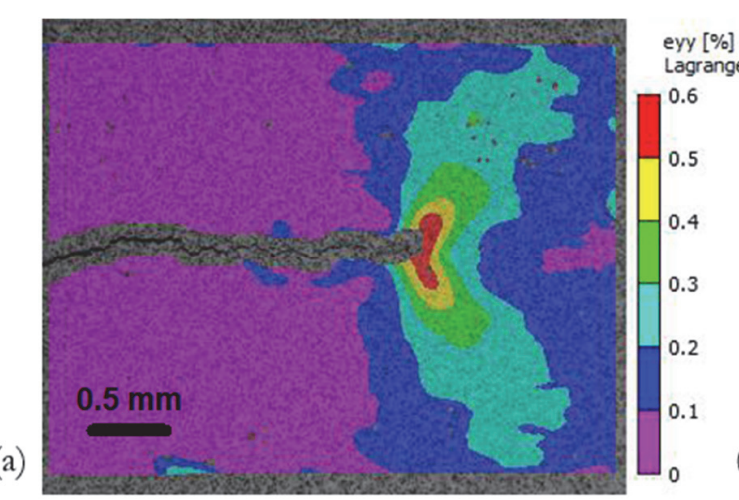

(b)

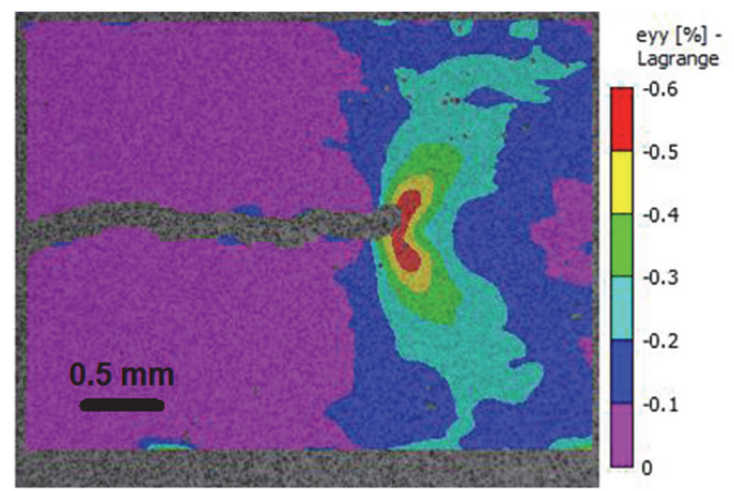

Figure 9: Strain map data for loading path 1' $\rightarrow$ 2' and unloading path 2' $\rightarrow$ 3' from loading block 3.
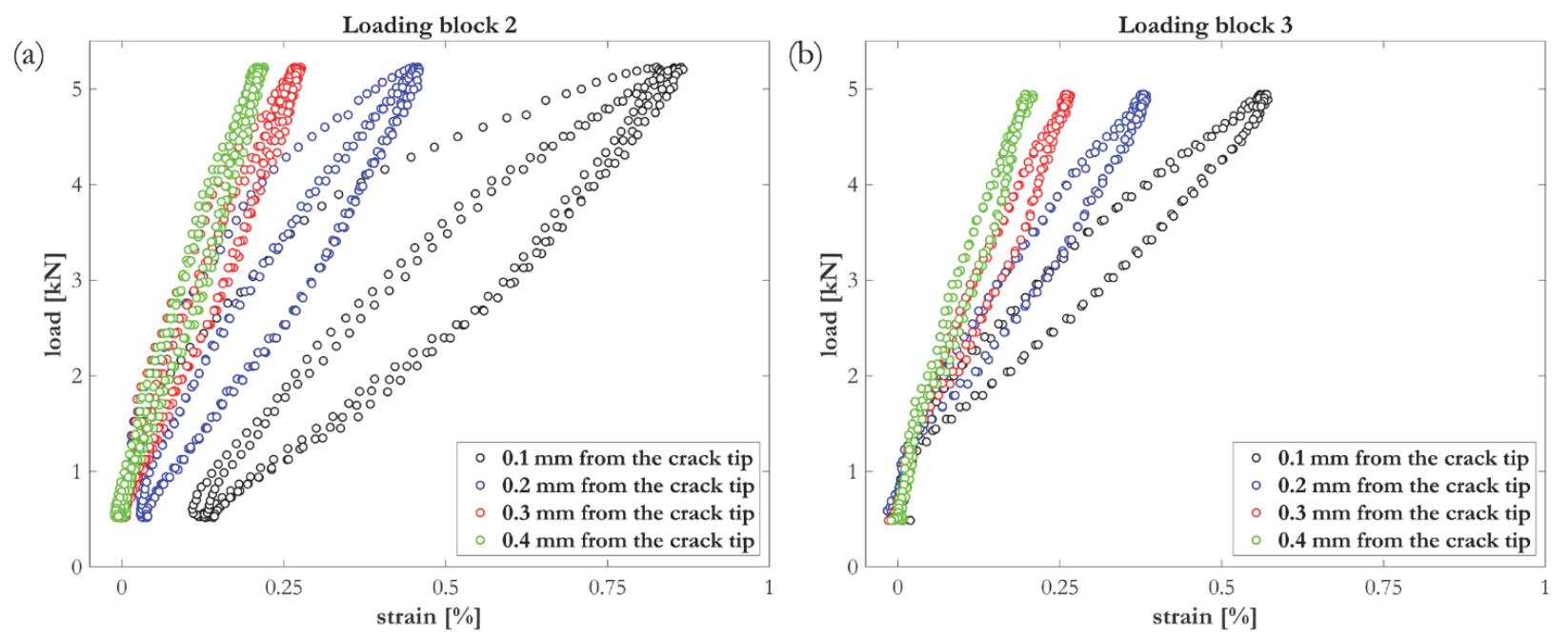

Figure 10: Strain behavior at different locations $\mathrm{mm}$ from the crack tip 


\section{CONCLUSIONS}

I $\mathrm{n}$ this paper, in situ strain measurements at near-tip region were successfully obtained by using the present methodology. For the current experiment, cyclic plastic deformation was observed in front of the near-tip region with a hysteretic response in which the plastic deformation induced during the loading path was totally or quasi-totally reverted during the unloading path, contributing directly to its fatigue damage since it is proportional to the strain range $\Delta \varepsilon$. It is worth empathizing that these strain measurements take into account nonlinear phenomena acting behind, at or ahead of the crack tip during the current fatigue crack propagation test. The extension of this study to other materials and general variable amplitude testing will be investigated in the future.

\section{REFERENCES}

[1] Willenborg, J., Engle, R.M. and Wood, H.A. (1971). A crack growth retardation model using an effective stress concept, AFFDL-TM-71-1-FBR.

[2] Hutchinson, J. W. (1989). A course on nonlinear fracture mechanics. Department of Solid Mechanics, Techn. University of Denmark.

[3] McClung, R. (1991). Crack closure and plastic zone sizes in fatigue, Fatigue \& fracture of engineering materials \& structures, 14(4), pp. 455-468. DOI: 10.1111/j.1460-2695.1991.tb00674.x.

[4] Castro, J.T.P. and Meggiolaro, M.A. (2016). Fatigue Design Techniques (in 3 volumes), CreateSpace, Scotts Valley, CA, USA.

[5] Zheng, X., Cui, H., Su, X., Engler-Pinto Jr, C. C. and Wen, W. (2013). Numerical modeling of fatigue crack propagation based on the theory of critical distances, Engineering Fracture Mechanics, 114, pp. 151-165. DOI: $10.1016 /$ j.engfracmech.2013.10.018.

[6] Paul, S. K. and Tarafder, S. (2013). Cyclic plastic deformation response at fatigue crack tips, International Journal of Pressure Vessels and Piping, 101, pp. 81-90. DOI: 10.1016/j.ijpvp.2012.10.007.

[7] Jingjie, C., Yi, H., Leilei, D. and Yugang, L. (2014). A new method for cyclic crack-tip plastic zone size determination under cyclic tensile load, Engineering Fracture Mechanics, 126, pp. 141-154. DOI: 10.1016/j.engfracmech.2014.05.001.

[8] Camas, D., Lopez-Crespo, P., Gonzalez-Herrera, A. and Moreno, B. (2017). Numerical and experimental study of the plastic zone in cracked specimens, Engineering Fracture Mechanics, 185, 20-32. DOI: 10.1016/j.engfracmech.2017.02.016.

[9] Besel, M. and Breitbarth, E. (2016). Advanced analysis of crack tip plastic zone under cyclic loading, International Journal of Fatigue, 93, pp. 92-108. DOI: 10.1016/j.ijfatigue.2016.08.013.

[10] Durán, J. A. R., Castro, J. T. P. and Filho, J. C. P. (2003). Fatigue crack propagation prediction by cyclic plasticity damage accumulation models, Fatigue \& Fracture of Engineering Materials \& Structures, 26(2), pp. 137-150. DOI: 10.1046/j.1460-2695.2003.00630.x.

[11] Sadananda, K. and Vasudevan, A. K. (2011). Review of environmentally assisted cracking, Metallurgical and Materials Transactions A, 42(2), pp. 279-295. DOI: 10.1007/s11661-010-0472-3.

[12] de Castro, J. T. P., Meggiolaro, M. A. and de Oliveira Miranda, A. C. (2005). Singular and non-singular approaches for predicting fatigue crack growth behavior, International Journal of Fatigue, 27(10-12), pp. 1366-1388.

DOI: $10.1016 /$ j.ijfatigue.2005.07.018.

[13] de Castro, J. T. P., Meggiolaro, M. A. and de Oliveira Miranda, A. C. (2009). Fatigue crack growth predictions based on damage accumulation calculations ahead of the crack tip, Computational Materials Science, 46(1), pp. 115-123.

DOI: $10.1016 /$ j.commatsci.2009.02.012.

[14] Ferreira, S. E., de Castro, J. T. P. and Meggiolaro, M. A. (2018). Fatigue crack growth predictions based on damage accumulation ahead of the crack tip calculated by strip-yield procedures, International Journal of Fatigue, 115, pp. 89106. DOI: $10.1016 /$ j.ijfatigue.2018.03.001.

[15] Sutton, M. A., Orteu, J. J. and Schreier, H. (2009). Image correlation for shape, motion and deformation measurements: basic concepts, theory and applications, Springer Science \& Business Media. DOI: 10.1007/978-0-387-78747-3.

[16] Tong, J., Lin, B., Lu, Y. W., Madi, K., Tai, Y. H., Yates, J. R. and Doquet, V. (2015). Near-tip strain evolution under cyclic loading: In situ experimental observation and numerical modelling, International Journal of Fatigue, 71, pp. 4552. DOI: $10.1016 /$ j.ijfatigue.2014.02.013. 
[17] Lu, Y. W., Lupton, C., Zhu, M. L. and Tong, J. (2015). In situ experimental study of near-tip strain evolution of fatigue cracks, Experimental Mechanics, 55(6), pp. 1175-1185. DOI: 10.1007/s11340-015-0014-4.

[18] Zhang, W. and Liu, Y. (2011). Plastic zone size estimation under cyclic loadings using in situ optical microscopy fatigue testing, Fatigue \& Fracture of Engineering Materials \& Structures, 34(9), pp. 717-727. DOI: $10.1111 /$ j.1460-2695.2011.01567.x.

[19] Carroll, J. D., Abuzaid, W. Z., Lambros, J., \& Sehitoglu, H. (2013). On the interactions between strain accumulation, microstructure, and fatigue crack behavior, International Journal of Fracture, 180(2), pp. 223-241. DOI: $10.1007 /$ s10704-013-9813-8.

[20] Elber, W. (1971). The significance of fatigue crack closure, In Damage tolerance in aircraft structures. ASTM International. DOI: 10.1520/STP26680S.

[21] Skorupa, M. (1998). Load interaction effects during fatigue crack growth under variable amplitude loading-a literature review. Part I: empirical trends, Fatigue \& Fracture of Engineering Materials \& Structures, 21(8), pp. 987-1006. DOI: 10.1046/j.1460-2695.1998.00083.x.

[22] Skorupa, M. (1999). Load interaction effects during fatigue crack growth under variable amplitude loading-a literature review. Part II: qualitative interpretation, Fatigue \& Fracture of Engineering Materials \& Structures, 22(10), 905-926. DOI: 10.1046/j.1460-2695.1999.00158.x.

[23] ASTM E 647-99. (2011). Standard test method for measurement of fatigue crack growth rates. ASTM International. [24] VIC-3D. (2010) Software, Correlated Solutions Inc. http://www.correlatedsolutions.com/.

[25] International Digital Image Correlation Society, Jones, E.M.C., Iadicola, M.A. (2018). A Good Practices Guide for Digital Image Correlation.

[26] Mughrabi, H. and Christ, H. J. (1997). Cyclic deformation and fatigue of selected ferritic and austenitic steels: specific aspects, ISIJ international, 37(12), pp. 1154-1169. DOI: 10.2355/isijinternational.37.1154. 